\title{
Vaccination hesitancy in the antenatal period: a cross-sectional survey
}

Paul Corben ${ }^{1 *}$ (D) and Julie Leask ${ }^{2}$

\begin{abstract}
Background: Recent reports of childhood vaccination coverage in Australia have shown steadily improving vaccination coverage and narrowing differences between highest and lowest coverage regions, yet the NSW North Coast consistently has the lowest coverage rates nationally. Better understanding of parents' vaccination attitudes and actions within this region may guide strategies to improve uptake. The antenatal period is when many parents explore and consolidate vaccination attitudes and so is pivotal for study.

Methods: Women attending public antenatal clinics at six NSW North Coast hospitals completed a 10-min cross-sectional survey capturing stage of decision-making and decisional-conflict as well as vaccination hesitancy, attitudes, intentions and actions. Unscored responses were analysed for individual items. Decisional conflict subscales were scored using published algorithms. For consented children, immunisation status was assessed at 8 months using the Australian Immunisation Register.

For Likert scale items, odds ratios and Fisher's exact, chi-squared and Chasson's tests assessed differences between subgroups. Wilcoxon rank-sum tests assessed differences between subgroups for items on scales of 0-to-10 and decisional conflict sub-scale scores.

Results: First-time mothers were 3 times more likely than others $(O R=3.40,95 \% \mathrm{Cl} 1.34-8.60)$ to identify as unsure, somewhat or very hesitant.

Most respondents (92.2\%) wanted their new baby to receive all recommended vaccinations. Many had high or moderate levels of concern about vaccine side effects (25.4\%), safety (23.6\%) and effectiveness (23.1\%).

Increased hesitancy was associated with decreased confidence in the schedule $(p<0.001)$, decreased trust in child's doctor $(p<0.0001)$, decreased perceived protection from disease $(p<0.05)$ and increased decisional conflict on all measured subscales $(p<0.0001)$. First-time mothers had higher decisional conflict on values clarity, support and uncertainty sub-scales.

By 8 months of age, $83.2 \%$ of infants were fully vaccinated. Those with none or a few minor concerns were over 8 times more likely than others to vaccinate on schedule $(\mathrm{OR}=8.7,1.3-56.7)$.

Conclusions: Importantly this study provides further strong justification to talk with women about vaccination during pregnancy and particularly to ensure that first-time mothers are offered assistance in making these important decisions, where indicated. Further research should focus on optimising the timing, content and delivery style of perinatal interventions.
\end{abstract}

Keywords: Vaccine hesitancy, Decisional conflict, Antenatal, Decision-making, Immunisation, Midwife

\footnotetext{
* Correspondence: paul.corben@ncahs.health.nsw.gov.au

'Director, North Coast Public Health, Mid North Coast Local Health District,

PO Box 126, Port Macquarie, NSW 2444, Australia

Full list of author information is available at the end of the article
}

(c) The Author(s). 2018 Open Access This article is distributed under the terms of the Creative Commons Attribution 4.0 International License (http://creativecommons.org/licenses/by/4.0/), which permits unrestricted use, distribution, and reproduction in any medium, provided you give appropriate credit to the original author(s) and the source, provide a link to the Creative Commons license, and indicate if changes were made. The Creative Commons Public Domain Dedication waiver (http://creativecommons.org/publicdomain/zero/1.0/) applies to the data made available in this article, unless otherwise stated. 


\section{Background}

Despite the wide acceptance of vaccination and the extensive body of supporting evidence, not all parents choose to vaccinate their children according to recommended schedules [1, 2]. As Kennedy et al. observed "High immunization rates are not the same thing as high confidence in vaccines" [3] and there is growing concern within public health agencies and some sectors of the community that vaccines are losing public confidence [4].

In 2015, the National Vaccine Advisory Committee concluded that as many as one in five United States parents were not fully confident in the safety or importance of vaccines [5]. In the United Kingdom in 2015, 24.5\% of surveyed parents were hesitant about vaccines and, for $79 \%$ of hesitant parents, confidence issues were the main driver of hesitancy [6]. In Australia, the proportion of parents expressing strong support for immunisation significantly decreased from $86.1 \%$ in 2001 to $64.8 \%$ in 2009/10 [7, 8]. Should this loss of strong confidence in vaccination translate to behaviour, it could threaten achievement of Australia's aspirational target of having 95\% of children fully vaccinated [9].

Vaccine safety scares, whether factual or fabricated, can erode confidence and motivate rapid and sustained reductions in coverage. Most infamously, the reporting of an alleged link between the measles-mumps-rubella (MMR) vaccine and autism in 1998 resulted in a dramatic fall in vaccine uptake and triggering of outbreaks in the United Kingdom, with MMR coverage falling from $91.8 \%$ in 1995-96 to $79.9 \%$ in $2003-04$, before climbing back to pre-scare levels of $92.1 \%$ in 2012-13 [10]. In Australia, reports of febrile reactions including convulsions in children under 5 years of age following vaccination with one of the three available influenza vaccines resulted in a "lasting sense of uncertainty and confusion" amongst some parents [11]. In the era of late modernity where, rather than relying on the advice of experts or authorities, individuals feel obliged to assess risks and modify their behaviours as new information becomes available, episodic undermining of confidence in vaccines could easily threaten high coverage levels [12].

Despite this somewhat bleak outlook, a recent report of childhood vaccination coverage in Australia showed steadily improving rates of vaccination coverage and narrowing of the difference between regions with the highest and lowest coverage [9]. While there is noted variability in the prevalence of recorded conscientious objections to vaccination coverage considered to be associated with clustering of people pursuing "alternate" lifestyles or having shared concerns about allopathic medicine [13, 14], other studies have concluded that likely contributors to variability in coverage include socio-economic status, barriers to access, incomplete recording of vaccinations and missed vaccination opportunities [15-17]. Two recent reports ranked the New South Wales (NSW) north coast lowest amongst Australia's thirty one Primary Health Network areas across three milestone age groups with $89.8 \%, 87.2 \%$ and $90.3 \%$ of children fully vaccinated at one, two and five years of age respectively in 2015/16 [18]. Better understanding of the vaccination attitudes, intentions and actions of parents within this region may help guide strategies to improve uptake of childhood vaccination.

While many studies have sought to unravel the impediments to vaccination decision-making, few have gathered information about when parents make vaccination decisions. Wroe et al. [19] sought the vaccination intentions of 195 women during third trimester of pregnancy and tracked their vaccination decisions. The vast majority $(88 \%)$ of women in that cohort made their decision during pregnancy and there was a strong association $(\eta$ $=0.87$ ) between antenatal intentions and vaccination action. Other studies have found that around 28\% of parents were undecided about vaccination before the birth of their child and a similar proportion remained hesitant or had doubts about vaccination after the birth of their child, frequently leading to delay or refusal of vaccination [20, 21]. Henrikson et al. observed significant reductions in maternal vaccine hesitancy from birth to 2 years and postulated that, because hesitancy fell as mothers' confidence in the safety and effectiveness of vaccines grew, the antenatal period and soon after delivery may be ideal times to provide support for parents making vaccination decisions [22]. These studies have provided empirical evidence that the antenatal period is a time when many parents explore and consolidate their vaccination attitudes and therefore presents as a pivotal period for study to improve our understanding of vaccination decisions.

This article reports the attitudes, intentions and vaccination behaviours of pregnant women attending antenatal clinics at public hospitals within the NSW north coast between September 2015 and July 2016.

\section{Methods}

The antenatal vaccination attitudes, intentions and actions reported here were captured in a screening survey intended to identify prospective interviewees who were undecided or hesitant about vaccination of their expected child (see Additional file 1). The survey was part of a mixed methods study with the primary aim of gaining an improved understanding of parents' experiences of vaccination decision-making during pregnancy and in the first 6 months of life.

Information about the study and the screening survey were distributed by administrative staff and/or midwives to parents attending public antenatal clinics in six hospitals on the NSW north coast. Clinics chose their preferred method to distribute study material. Parents either completed the 
survey and placed it in a secure box at the clinic or posted it to the research team in a sealed postage-paid envelope. Return of the completed survey was accepted as consent. Additionally, the survey form sought written consent for follow-up of vaccination records and willingness to participate in antenatal and postnatal interviews.

The survey included items from validated instruments measuring stage of decision-making [23], decisionalconflict [24], vaccine hesitancy [21, 25, 26], vaccine beliefs and attitudes [7, 27-29], novel items [30] and basic demographics. O'Connor describes decisional conflict as "a state of uncertainty about a course of action" which may be characterised by "verbalized uncertainty about choices, verbalization of the undesired consequences of alternatives; vacillation between choices, and delayed decision making." [31]. Vaccine hesitancy may be described as "a delay in acceptance or refusal of vaccination despite availability of vaccination services." [32].

Where necessary, items were modified to align with Australian parlance eg the word "shot" was replaced with "vaccine" in items drawn from the Parents Attitudes to Childhood Vaccination (PACV) [21]. Items relating to the informed, values clarity, support and uncertainty sub-scales of the Decisional Conflict Scale [31] were included. The survey contained 42 questions, with 36 requiring response on 5 -item or 6 -item Likert scales as per scales used by item developers. Two questions adapted from the PACV and one from Kennedy et al. [28] sought a response on the scale 0 to 10 , anchored at each end by descriptors. The survey took approximately $10 \mathrm{~min}$ to complete.

Descriptive analyses of unscored responses were completed for demographic items and items grouped according to their focus e.g., vaccination attitudes and intentions; risk considerations; social influences or decisional aspects. Decisional Conflict sub-scales were scored according to algorithms used in the scale's development and validation [24].

Immunisation actions of consenting parents were identified by checking the child's record on the Australian Immunisation Register (AIR). Immunisation completeness was assessed at 8 months of age in accordance with AIR due and overdue rules and scored as percentage of days unvaccinated in a manner similar to that used by Opel et al. Children were grouped according to percentage of days under-vaccinated [21]. The birth dose of hepatitis B vaccine was not included in completeness calculations and no allowance was made for catch-up schedules. Vaccination completeness was assessed for diphtheria, tetanus, pertussis, polio, haemophilus influenza $b$, hepatitis $B$, pneumococcal disease and rotavirus [33].

Analyses were conducted using Microsoft Excel and SAS software Version 9.4 [34]. Odds Ratios (OR), Fisher's exact test or Chi-squared tests were to assess differences in proportions. The Wilcoxon rank-sum test was used to assess differences between subgroup median scores when responses were measured on scales of 0 to 10 and for the decisional conflict sub-scale scores. Because rank-sum statistics are influenced by sample size and hence are not readily compared across studies, mean score and scale values and normal-approximation confidence intervals are reported for relevant items. Percentages exclude missing values (non-respondents).

The study was approved by the North Coast NSW Human Research Ethics Committee (LNR116) on 24 April 2015.

\section{Results}

Overall findings from the survey about vaccination attitudes, intentions, social influences and risk considerations are summarised in Table 2.

\section{Demographics}

Surveys were completed by 231 expectant mothers attending antenatal clinics between 28 September 2015 and 27 July 2016 and 100 (43\%) respondents consented to follow-up of their child's vaccinations. The 231 respondents represented approximately $5.9 \%$ of the estimated births in the region during in the same period and all participating clinics (range: 9-98 per clinic).

Respondents' age distribution was similar to that of North Coast mothers delivering in $2015(p=0.404)$ [35]. Compared to Australian Bureau of Statistics 2011 Census of Population and Housing estimates, the sample included a higher proportion of women completing Year 12 (73.1\% vs $55.7 \%)$ and a higher percentage ( $80.8 \%$ vs $51.2 \%$ ) completing a post-secondary qualification (trade certificate, bachelor's degree or higher) (Table 1).

\section{Vaccination attitudes, intentions and antenatal actions}

Support for childhood vaccination was high, with no significant differences in strong support based on parity $(p=0.304)$, highest school level $(p=0.184)$ or having a post-secondary qualification $(p=0.826)$.

Overall, $65.3 \%$ of respondents assessed themselves as "not at all hesitant" about childhood vaccination, $25.3 \%$ as "not too hesitant", $3.6 \%$ were somewhat hesitant, $2.2 \%$ were very hesitant and $3.6 \%$ were not sure. First-time mothers were 3 times more likely than experienced mothers $(\mathrm{OR}=$ 3.40, 95\% CI 1.34-8.60) to describe themselves as unsure, somewhat or very hesitant (Fig. 1 and Table 2).

Strong support for childhood vaccination decreased with increasing self-assessed hesitancy, dropping from 93. $2 \%$ among 'not at all hesitant' respondents to $64.9 \%$ of the 'not too hesitant' and $28.6 \%$ of the very/somewhat hesitant or unsure (Chassan's test for trend, $p<0.005$ ) [36].

Overall $92.2 \%$ of respondents indicated that they wanted their new baby to receive all recommended vaccinations, with no significant differences based on parity 
Table 1 Demographics of respondents

\begin{tabular}{|c|c|}
\hline Demographic items & Number (\%) \\
\hline \multicolumn{2}{|l|}{ Age group $(N=222)$} \\
\hline 18-24 years & $43(19.4 \%)$ \\
\hline $25-29$ years & $63(28.4 \%)$ \\
\hline $30-34$ years & $73(32.9 \%)$ \\
\hline $35-39$ years & $35(15.8 \%)$ \\
\hline 40-44 years & $8(3.6 \%)$ \\
\hline \multicolumn{2}{|l|}{ First baby $(N=228)$} \\
\hline Yes & $80(35.1 \%)$ \\
\hline No & $148(64.9 \%)$ \\
\hline \multicolumn{2}{|l|}{ Trimester completed survey form $(N=223)$} \\
\hline 1st Trimester & $2(0.9 \%)$ \\
\hline 2nd Trimester & $85(38.1 \%)$ \\
\hline 3rd Trimester & $136(61.0 \%)$ \\
\hline \multicolumn{2}{|l|}{ Highest year of secondary schooling $(\mathrm{N}=223)$} \\
\hline Year 12 & $163(73.1 \%)$ \\
\hline Year 11 & $13(5.8 \%)$ \\
\hline Year 10 & $39(17.5 \%)$ \\
\hline Year 9 & $6(2.7 \%)$ \\
\hline Other & $2(0.9 \%)$ \\
\hline \multicolumn{2}{|l|}{ Post-secondary qualification $(N=219)$} \\
\hline Yes, trade certificate or apprenticeship & $51(23.3 \%)$ \\
\hline Yes, other qualification & $126(57.5 \%)$ \\
\hline No, still studying for 1 st qualification & $8(3.7 \%)$ \\
\hline No & $34(15.5 \%)$ \\
\hline \multicolumn{2}{|c|}{ Highest post-secondary qualification $(N=183)$} \\
\hline Professional fellowship qual & $3(1.6 \%)$ \\
\hline Master's degree & $10(5.5 \%)$ \\
\hline Bachelor's degree & $58(31.7 \%)$ \\
\hline Assoc degree or diploma & $26(14.2 \%)$ \\
\hline Cert III or Cert IV & $74(40.4 \%)$ \\
\hline Cert II or Cert I & $12(6.6 \%)$ \\
\hline
\end{tabular}

$(p=0.077)$, level of schooling completed $(p=0.242)$ or completion of a post-secondary qualification $(p=0.782)$. When asked about vaccination intentions and vaccine concerns, $42.5 \%$ stated they had no concerns, $50.4 \%$ had a few minor concerns, $2.2 \%$ had lots of concerns and 4 . $9 \%$ were unsure about vaccinating their baby or would delay or refuse some or all vaccines.

Amongst those who wanted their child to receive all vaccines, those who identified as 'not too hesitant' were 8 times more likely ( $\mathrm{OR}=8.2,3.7-17.9$ ) to have a few or lots of concerns about vaccine safety than the 'not at all hesitant'.

While $48.5 \%$ of respondents indicated they had received or planned to receive an influenza vaccination during pregnancy, $87.4 \%$ indicated they had or planned to receive a pertussis vaccination during pregnancy, with no differences based on parity. Those who reported any level of hesitancy about childhood vaccination were $45 \%$ less likely to report having or planning to have influenza vaccine $(\mathrm{OR}=0.55,0.32-0.95)$.

Those who indicated any level of hesitancy were more likely to report ever delaying a vaccine $(\mathrm{OR}=9.2,1.8$ 46.6) and more likely to report ever deciding against vaccinating a child $(\mathrm{OR}=9.5,1.0-87.3)$ for reasons other than illness or allergy.

\section{Social influences}

Social influences were important in respondents' vaccination decisions. Mothers who expressed any level of hesitancy (compared to 'not at all hesitant') were less likely to strongly agree that people important to them supported them to vaccinate their child $(\mathrm{OR}=0.21,0$. 11-0.41) and less likely to strongly agree that people important to them would vaccinate their own child $(\mathrm{OR}=$ $0.21,0.12-0.37$ ).

However, those who strongly agreed that "access to government family support payments is important in vaccination decisions" were not more likely to be primiparous, $(p=0.850)$, concerned about vaccines $(p=0$. $097)$ or report any level of hesitancy $(p=0.561)$.

Overall, respondents indicated a high level of trust in their child's doctor, with $84.5 \%$ rating their trust as 8 or above. There were no differences in trust rating based on parity $(p=0.221)$, level of school completion $(p=0$. $815)$ or completion of post-secondary qualifications $(p=$ 0.225 ). Respondents who strongly supported childhood vaccination showed higher levels of trust (mean $=9.30$, 9.11-9.48) than those who generally supported childhood vaccination $(7.56,6.82-8.29)$ and those who opposed or were ambivalent $(4.22,1.57-6.88)(p<0.0001)$. Similarly, those who were 'not at all hesitant' reported higher levels of trust $(9.43,9.25-9.61)$ than the not too hesitant' $(8.51,8.07-8.95)$ and the very/somewhat hesitant or unsure $(5.76,4.23-7.30)(p<0.0001)$ (Fig. 2).

\section{Risk considerations}

Almost all respondents agreed that the benefits of vaccines outweighed the risks, with $69.6 \%$ strongly agreeing and a further $21.8 \%$ agreeing. Only $2.8 \%$ disagreed or strongly disagreed. First-time mothers were less sure about the balance of risks, with $12.0 \%$ compared to $2.7 \%$ of experienced mothers neither agreeing nor disagreeing that benefits outweigh risks $(\mathrm{OR}=4.84,1.44-16.29)$ (Table 2). The 'not too hesitant' were $88 \%$ less likely than the 'not at all hesitant' to agree that benefits outweigh risks (OR $=0.12,0.02-0.61)$.

About a quarter of respondents had high or moderate levels of concern about potential side effects (25.4\%), concerns childhood vaccines might not be safe (23.6\%) 


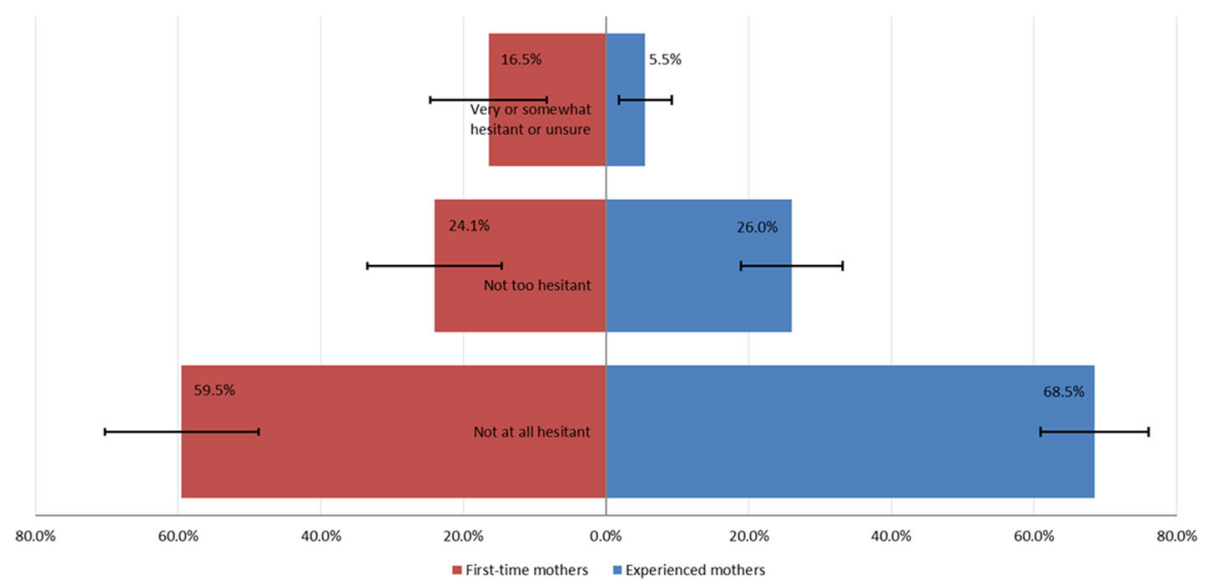

Fig. 1 Self-assessed hesitancy about childhood vaccines, expectant mothers NSW north coast 2015-16

and concerns that a vaccine might not prevent disease (23.1\%), with no differences based on parity or highest year of schooling (Table 2). Table 3 summarises increasing likelihood of concern about vaccine safety, vaccine side-effects and vaccine effectiveness as respondents' levels of hesitancy increased.

Overall, respondents were confident that following the recommended vaccination schedule was good for their child with $85.4 \%$ rating 8 or more (on scale $0-10$ ) and averaging 8.83 (8.54-9.13). There was a downward gradient in respondents' confidence in the schedule with increasing hesitancy $(p<0.001)$ and with decreasing overall support for vaccination $(p<0.0001)$. More hesitant respondents reported lower likelihood of contracting a vaccine-preventable disease in Australia if unvaccinated with significant differences in perceived likelihood of disease between the 'not at all hesitant' and 'not too hesitant' $(p=0.046)$ and between the 'not too hesitant' and 'very/ somewhat hesitant and unsure' $(p=0.019)$.

\section{Decision-making aspects}

At the time of completing the survey, $80.7 \%$ (75.6\%-85. $8 \%$ ) of respondents had made up their mind and were unlikely to change and an additional $7.9 \%(4.4 \%-11.4 \%)$ had made a decision but were willing to reconsider. First-time mothers (77.5\%) were less likely than experienced mothers $(94.5 \%)$ to have made their decision (including those willing to reconsider) at the time of completing the survey $(p=0.0003)$.

About one-third (35.5\%) of first-time mothers completing the survey up to the end of second trimester had not made a decision compared to $5.8 \%$ of experienced mothers $(p=0.0015)$. For those completing the survey during their third trimester, the proportions of 'undecided'
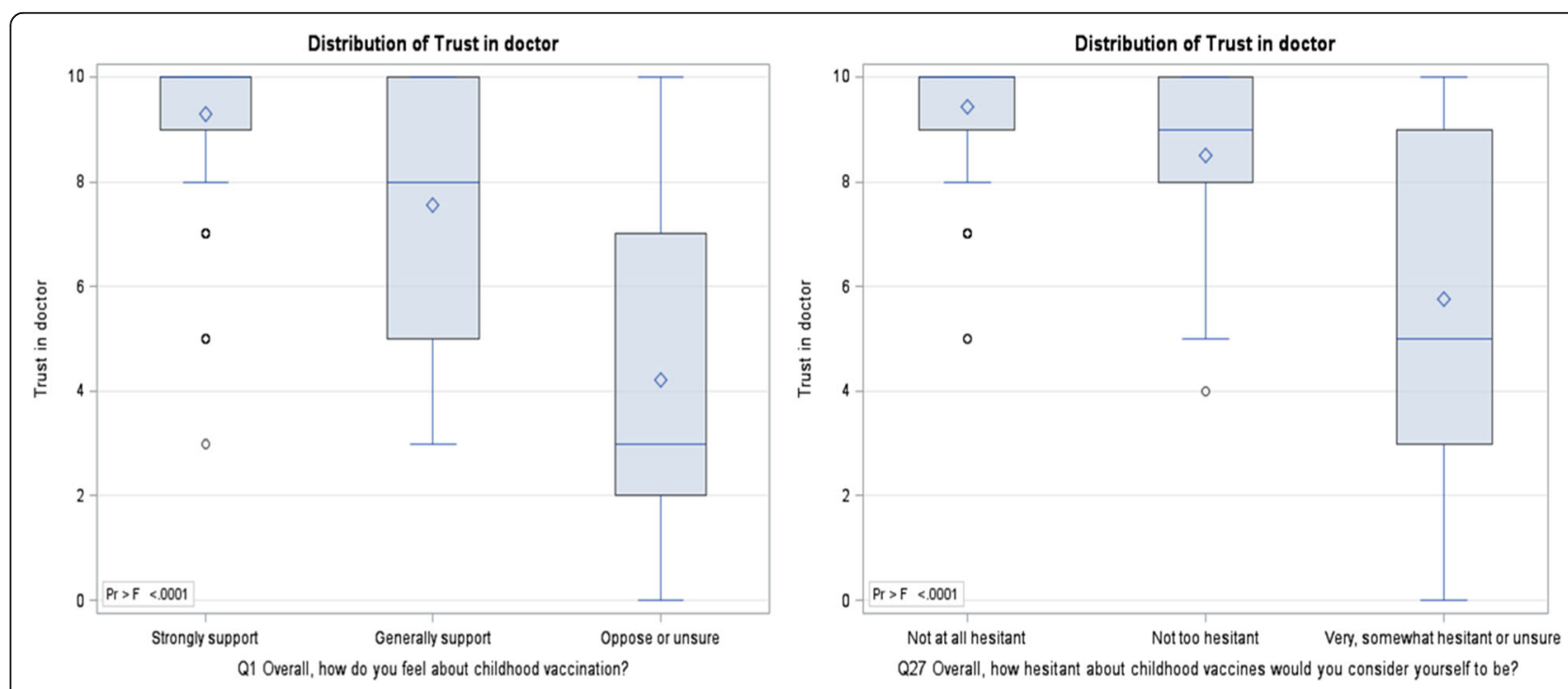

Fig. 2 Distribution of Trust in doctor (Q29) by support for vaccination (Q1) and self-assessed hesitancy (Q27) 


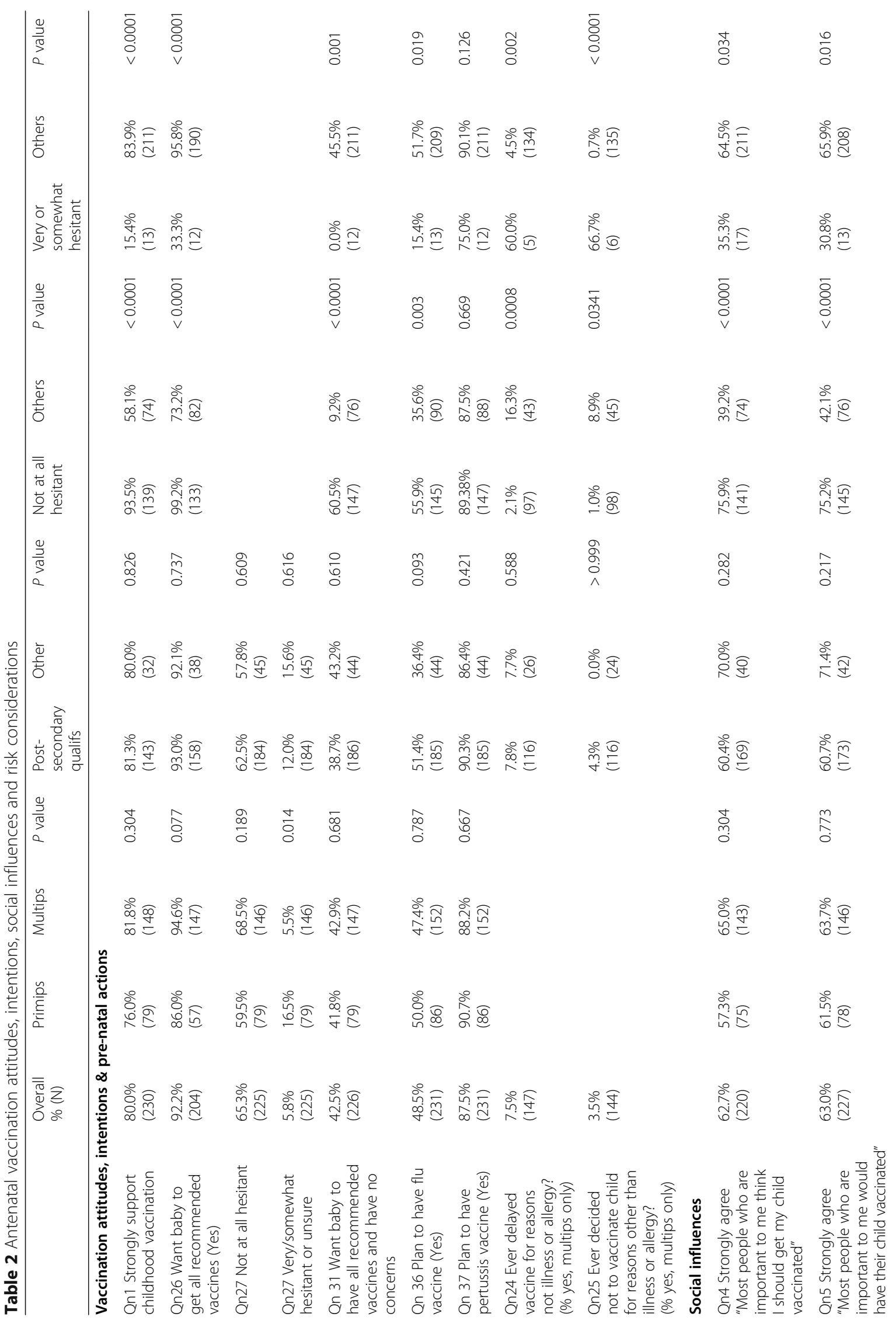


Corben and Leask BMC Public Health (2018) 18:566

Page 7 of 13

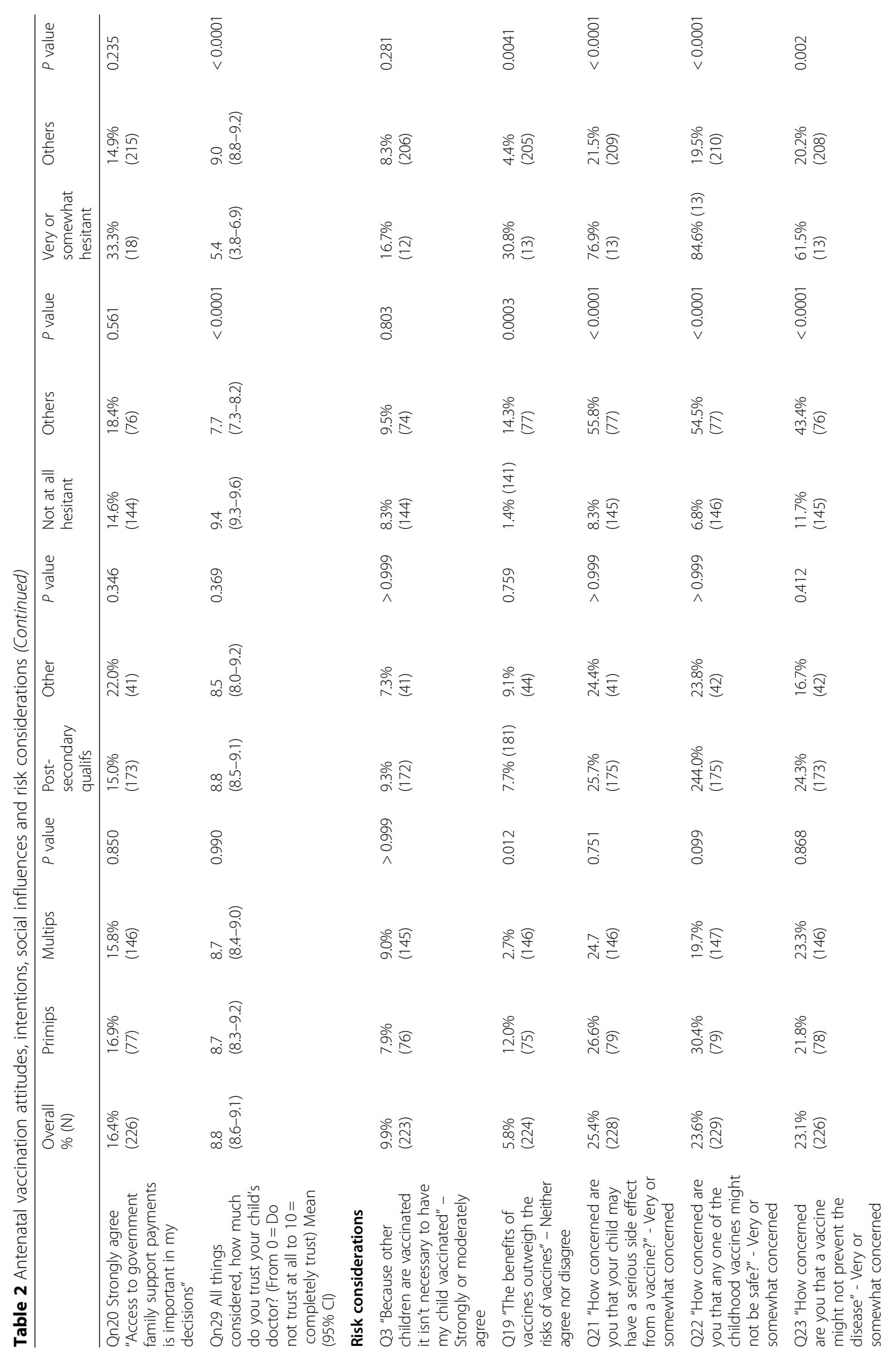




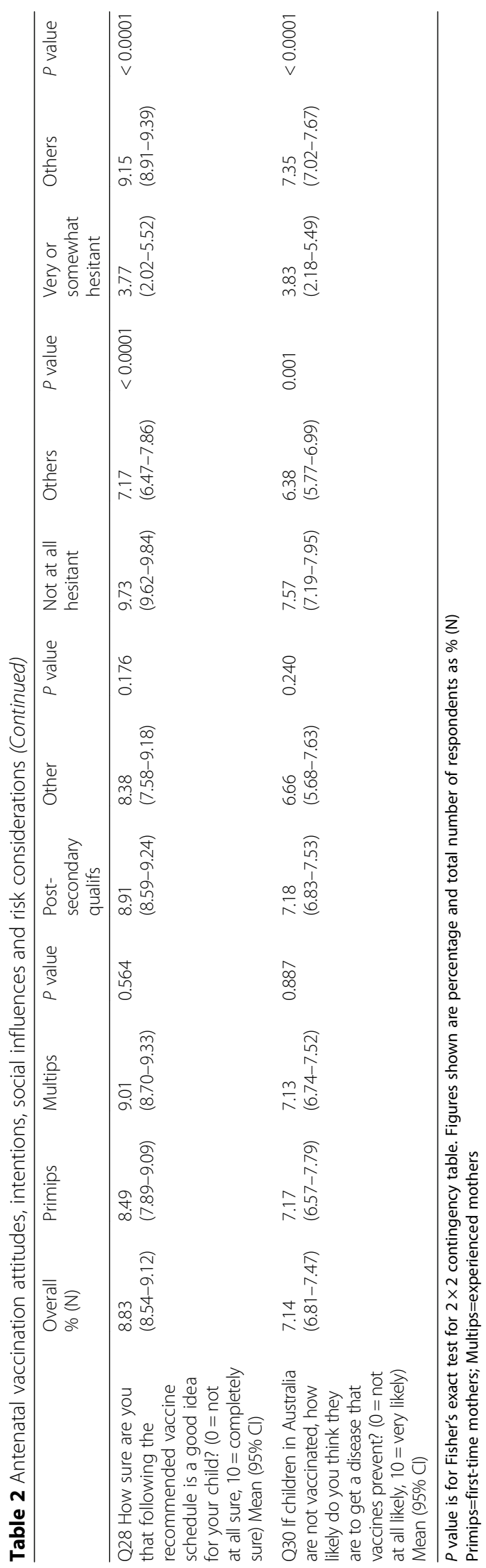


Table 3 Odds ratios - vaccine concerns and decisional conflict by self-assessed hesitancy, expectant mothers

\begin{tabular}{|c|c|c|c|}
\hline & $\begin{array}{l}\text { Not at all hesitant } \\
\text { (referent) }\end{array}$ & $\begin{array}{l}\text { Not too } \\
\text { hesitant }^{a}\end{array}$ & $\begin{array}{l}\text { Very or somewhat hesitant or } \\
\text { unsure }^{\mathrm{a}}\end{array}$ \\
\hline \multicolumn{4}{|l|}{ Vaccine concerns } \\
\hline Very/somewhat concerned vaccine might have side effect & Referent & $11.1(5.0-24.4)$ & $27.7(9.1-84.6)$ \\
\hline Very/somewhat concerned vaccine might be unsafe & Referent & $11.8(5.1-27.0)$ & $43.5(13.2-143.3)$ \\
\hline $\begin{array}{l}\text { Very/somewhat concerned vaccine might not prevent } \\
\text { disease }\end{array}$ & Referent & $4.7(2.2-9.8)$ & $10.0(3.7-27.3)$ \\
\hline \multicolumn{4}{|l|}{ Decisional conflict sub-scale ${ }^{b}$} \\
\hline Informed subscale (score $\geq 37.5$ ) & Referent & $7.9(3.2-19.3)$ & $12.0(4.3-33.5)$ \\
\hline Values clarity subscale (score $\geq 37.5$ & Referent & $3.7(1.5-8.8)$ & $11.4(4.4-29.5)$ \\
\hline Support sub-scale (score $\geq 37.5$ ) & Referent & $13.1(2.7-62.9)$ & $43.7(9.0-213.0)$ \\
\hline Uncertainty subscale (score $\geq 37.5$ ) & Referent & $17.4(3.8-80.4)$ & $85.4(17.7-413.7)$ \\
\hline
\end{tabular}

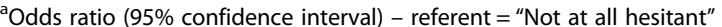

${ }^{b}$ Decisional conflict sub-scale scores $\geq 37.5$ are associated with decision delay or feeling unsure about implementation

mothers decreased to $14.9 \%$ for first-timers and to $4.4 \%$ for experienced mothers $(p=0.0086)$.

Table 3 reflects the strong influence of increasing levels of self-assessed hesitancy on decisional conflict sub-scale scores. The 'not at all hesitant' had significantly lower median scores $(p<0.0001)$ on each of the four decisional conflict subscales than those who identified as 'not too hesitant' (Fig. 3). The 'not too hesitant' had similar scores to those rating themselves as 'very/ somewhat hesitant or unsure' for the informed ( $p=0.3856)$, values clarity $(p=0.3513)$ and support $(p=0.3165)$ sub-scales but lower median scores on the uncertainty subscale $(p=0.0169)$.

While first-time and multiparous mothers had similar median scores on the informed sub-scale $(p=0.1306)$, first-time mothers displayed higher decisional conflict on the other three sub-scales (values clarity $p=0.0092$, support $p=0.0315$ and uncertainty $p=0.0033$ ).
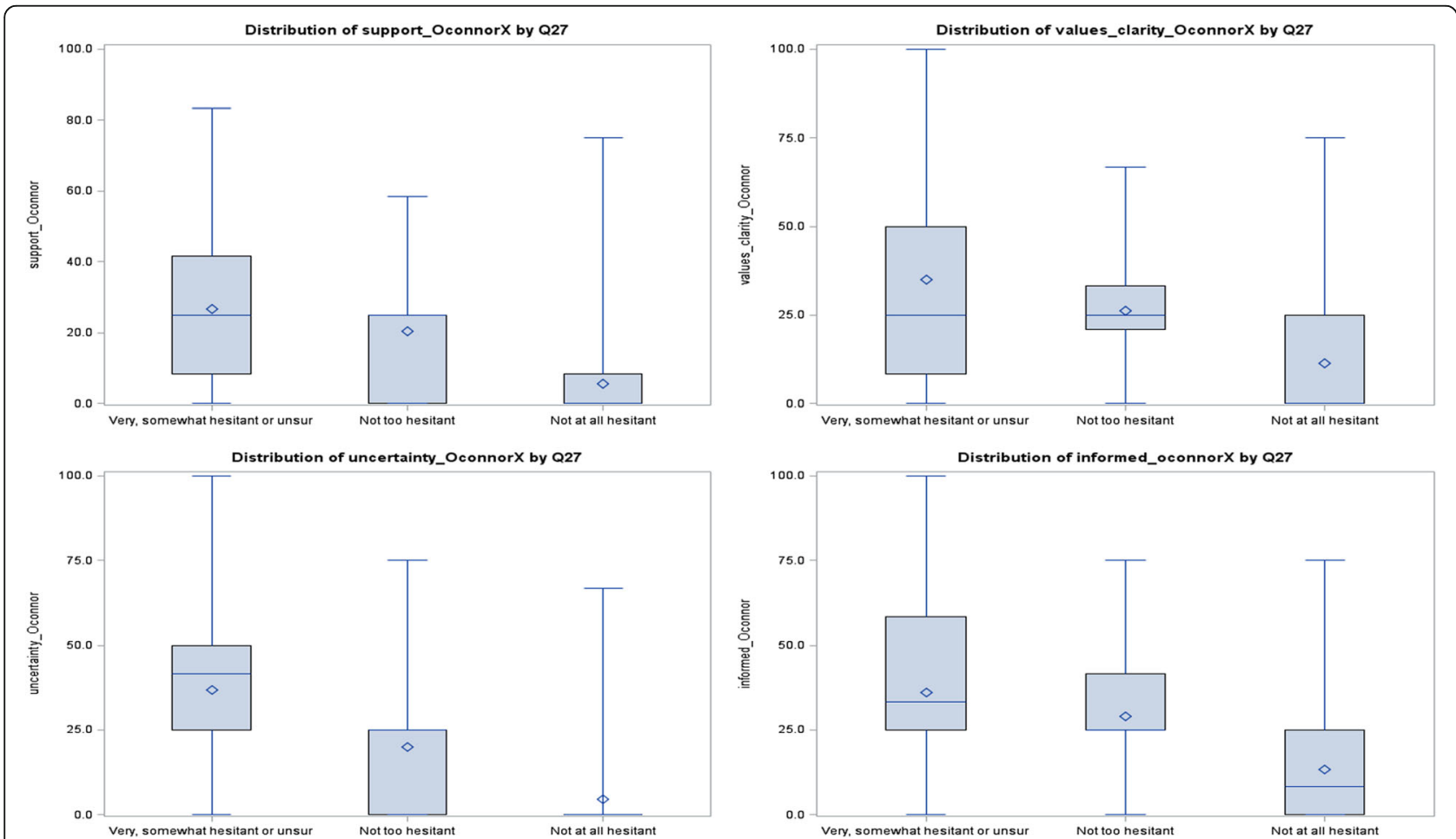

Fig. 3 Decisional conflict subscales by self-rated vaccine hesitancy.

Note: Mean scores are displayed as these are more readily interpreted and are not affected by sample size as are rank sum statistics. Decisional conflict sub-scale scores $\geq 37.5$ are associated with decision delay or feeling unsure about implementation 


\section{Immunisation outcomes}

One hundred women (43.7\% of respondents) consented to access of their babies' vaccination records, with AIR records for 101 infants able to be accessed (including two sets of twins). By 8 months of age, $83.2 \%$ of the infants were fully vaccinated within 30 days of the recommended date for each vaccine (i.e., zero days underimmunised) and a further $12.1 \%$ had immunised their baby after minor delay ( $<10 \%$ of follow-up days).

There was no difference detected in vaccination timeliness of babies of first-time mothers and experienced mothers $(p=0.242)$ nor between those who considered themselves 'not at all hesitant' and others $(p=0.705)$. Those with no concerns or a few minor concerns were over 8 times more likely to vaccinate on schedule than others $(\mathrm{OR}=8.7,1.3-$ 56.7) and those with a few concerns were just as likely to vaccinate on time as those with no concerns $(\mathrm{OR}=1.4,0.5-$ 4.5). Similar to Danchin et al., we detected no consistent correlation between uptake of maternal vaccines and infants' vaccination timeliness, with no difference in the odds of ontime infant vaccination for those choosing maternal influenza vaccination compared to those without $(\mathrm{OR}=1.78,0$. 63-4.99), on-time infant vaccination and maternal pertussis vaccination $(\mathrm{OR}=0.71,0.08-6.34)$, or on-time infant vaccination for those choosing both maternal influenza and pertussis vaccination $(\mathrm{OR}=1.65,0.59-4.64)$ [37].

There were no systematic differences between those consenting to vaccination follow-up and others according to parity, support for vaccination, trust in doctors, clinic group, concerns about vaccine side effects, self-assessed hesitancy, vaccination intention or stage of decision. Lack of variability in the vaccination actions of the respondents may reflect selection bias, with those completing surveys being more supportive of vaccination.

\section{Discussion}

This study confirms that most expectant mothers make decisions about vaccination before or during their pregnancy. As in similar studies [19, 37], we found that the overwhelming majority (81\%) of women attending antenatal clinics reported they had made a firm decision about vaccination of their expected child and a further $8 \%$ indicated that while they had made a decision, they might reconsider it before acting. Fewer first-time mothers (77.5\%) than experienced mothers $(94.5 \%)$ reported making a decision before or during pregnancy. About a third (35. $5 \%$ ) of first-time mothers were undecided during their second trimester and by third trimester one in seven (14.9\%) first-time mothers had still not decided about vaccinating their newborn. First-time mothers were 5 times more likely to be unsure that the benefits of vaccines outweigh their risks and 3 times more likely to declare they were somewhat/very hesitant or unsure about vaccinating their child.

We believe this is the first study that has assessed the decisional conflict experienced by pregnant women about vaccination of their unborn child. First time mothers had significantly higher median scores on three of four decisional conflict sub-scales (values clarity, support and uncertainty sub-scales), placing them at higher risk of decisional delay or feeling unsure about implementing their decisions.

These findings suggest there may be benefit from engaging with women about vaccination decisions during family planning and early in pregnancy and particularly so for women expecting their first child. Midwives are uniquely well-placed to support expectant and new mothers to make informed decisions about maternal and infant vaccination. However, some midwives find aspects of a vaccination advocacy role challenging due to the need to reconcile professional preferences for women's autonomy in decision-making or, for a significant minority, holding concerns about the safety, necessity and timing of vaccinations but working within the context of strident public health advocacy for timely vaccination of infants [38-40]. Despite these challenges, significant positive associations between provision of immunisation education and support during the antenatal period and uptake of childhood immunisation have been demonstrated in a range of settings including within a cluster randomised trial in Japan and cross-sectional studies in Nigeria and Cameroon [41-43].

While most $(80 \%)$ of respondents were strong supporters of vaccination and over $90 \%$ agreed that the benefits of vaccines outweigh the risks, a quarter expressed concern that a vaccine may not be safe, that their child could suffer serious side-effects or that the vaccine may not protect against the targeted diseases. Compared to the "not at all" hesitant, other pregnant women were 14 times more likely to be concerned about vaccine safety, 16 times more likely to be concerned about side-effects and 6 times more likely to have concerns about vaccine effectiveness. We found that even those who were "not too hesitant" expressed much higher levels of concern about safety, side-effects and effectiveness.

We also found that any level of stated hesitancy was associated with an $80 \%$ reduction in the likelihood of having important social contacts who supported vaccination and a 9-fold greater likelihood of ever delaying or refusing a child's vaccination for reasons other than illness or allergy. These findings portray the complexity and impact of psychosocial and other factors on pregnant women's immunisation attitudes, intentions and behaviours [44]. The findings also highlight the frailty underlying high uptake of vaccines and high levels of support for vaccination despite underlying safety concerns [3]. This confidence gap 
poses a risk to high coverage should a vaccine safety scare emerge and reflects the interplay between public confidence in vaccination and vaccine hesitancy, particularly in response to vaccine safety scares [45].

During the development of our survey, the Australian government announced its "No Jab, No Pay" policy that removed non-medical exemptions from eligibility criteria for certain family assistance payments [46]. Consequently, we included a question to gauge the importance of such policies in participants' vaccination decisions. In our sample, we found no association between importance of such policies with levels of concern about vaccines or selfassessed hesitancy. Despite claims of wide and significant impact of the policy since its introduction, it seems the policy will struggle to achieve its objective of addressing vaccine refusal and that other approaches will be needed to address hesitancy and refusal.

We observed large, statistically significant and consistent differences between those who described themselves as 'not too hesitant' and the 'not at all hesitant' and frequently we found no significant difference between the very/somewhat hesitant or unsure and the 'not too hesitant' group. This is of interest as the PACV scoring algorithm combines responses of 'not at all hesitant' and 'not too hesitant' as the non-hesitant response and these categories add zero to the overall hesitancy score, suggesting that this may reduce the sensitivity and specificity of the measure.

While there is need for robust and comprehensive measures of vaccine hesitancy for use in research settings, there is an ongoing need for a simple, sensitive and specific tool for routine use by immunisation providers. Our findings suggest that an algorithm combining a question about the stage of decision with another about self-rated hesitancy may provide a simple and pragmatic approach for use in busy service settings. The algorithm could simply identify parents who reflected any stated level of hesitancy or who have not yet made a final decision about vaccinating their newborn child. Such a tool could be evaluated for its capacity to help professionals identify when parents might want further engagement.

The optimal timing of screening for vaccination hesitancy is unknown. One view would suggest screening be conducted as early as possible during family planning and pregnancy, especially for first-time parents, to allow maximum time to resolve parents' concerns. However, we have identified that higher rates of hesitancy in early pregnancy appear to resolve naturally for most mothers as they near birth. Nevertheless, with $15 \%$ of primiparous women remaining hesitant there appears to be potential to target interventions in the antenatal period to improve vaccination timeliness. In particular, in our sample those with more concerns were less likely to be timely with vaccination. Additionally, it is not entirely clear what the interventions should involve. Danchin et al. recommended that additional research was needed to identify items that highlight parents' vaccine safety concerns as these appear to feed hesitancy and decisional delay [37]. Vannice et al. found that providing information increased positive maternal attitudes and beliefs about vaccine safety and confidence but no change in perceived necessity for vaccination. Participants in that study expressed a clear preference for receipt of information before vaccinations were due, either during pregnancy or soon after delivery [47]. In a clusterrandomised controlled trial, Saito and colleagues found that mothers who received a series of short, interactive information sessions during pregnancy, soon after delivery and when the baby was 1 month old reported improved positive injunctive social and descriptive norms (moral perceptions of what most people do and what an individual should do, respectively) and increased their perceptions of vaccine benefits [48] and were more likely than controls to vaccinate their child with mandated, but not voluntary, vaccines [43]. However, the approach taken and content of information sessions needs to be chosen carefully. 'Knowledge deficit' approaches to address vaccine hesitancy have not been successful, [49] and poorly executed attempts to correct misinformation can backfire [50]. Additionally, debate persists about whether presumptive approaches are more successful than participatory ones [51, 52]. Some studies have found that introducing information that challenges existing beliefs can increase deliberation, perhaps delaying decisions indefinitely. Consequently, it is likely that optimal strategies will need to tailor information and approach to individuals' needs and thinking styles - clearly a significant challenge in busy clinical settings [44, 53]. Regardless, this study's findings suggest the perinatal period is a potentially fruitful time for working with parents to prevent future vaccine delay and rejection. For this to occur, optimised interventions will need to be acceptable to those delivering care, including midwives, GPs and other providers of antenatal care and education and equip providers with tools to address concerns about vaccination whilst maintaining parents' trust [54].

This study has some limitations. Our wish to reduce respondent burden and our focus on screening for undecided parents meant that we did not retain all PACV items nor the items for the effective decision sub-scale. Consequently, we were unable to calculate summary hesitancy and decisional conflict measures. Due to the methods used to distribute the survey through the clinics, women with pro-vaccination attitudes may have been more inclined to complete the survey and this may have resulted in an elevated prevalence of pro-vaccination attitudes and limited variability in vaccination uptake, reducing our ability to identify important contributors to 
vaccination hesitancy amongst pregnant women. The study allowed clinics to choose their own method of survey distribution. We noted very low response rates amongst clinics that used passive means to distribute surveys and collect responses, reducing representativeness from across the region. Those clinics that actively encouraged mothers to complete and return the survey whilst in the waiting room had very much higher return rates.

\section{Conclusion}

We have documented important contributions to a more complete understanding of vaccination decision-making by pregnant women, highlighted gradients of vaccine hesitancy not previously reported and demonstrated associations between decisional-conflict sub-scales and vaccination attitudes, behaviours and actions. Importantly this study provides further strong justification to talk with women about vaccination during pregnancy and particularly to ensure that first-time mothers are offered assistance in making these important decisions. To accommodate the complexity of these settings, further research should focus on optimising the timing, content and delivery style of perinatal interventions that are acceptable to those providing care and that address the specific concerns of parents who are unsure about vaccinating their newborn child.

\section{Additional file}

Additional file 1: Vaccine Decision Journeys, Survey instrument, instructions and consent form. (PDF $587 \mathrm{~kb}$ )

\section{Abbreviations}

AIR : Australian Immunisation Register; NSW: New South Wales (a state on the east coast of Australia); OR: Odds Ratio; PACV: Parents Attitudes to Childhood Vaccination

\section{Acknowledgements}

The authors gratefully acknowledge the assistance of the midwives and administrative staff who distributed and collected study materials and the women attending antenatal clinics who participated in the study.

\section{Funding}

No specific funding was provided for this study. As a postgraduate research student, PC has applied for and received small grants $(<\$ A \cup D 1,500)$ from University of Sydney and in-kind support from the Mid North Coast Local Health District to support his candidature.

\section{Availability of data and materials}

Access to the original data of this study is dependent upon ethical approval and NSW Ministry of Health unit record data release policies.

\section{Authors' contributions}

PC created, reviewed and refined the survey instrument, conducted statistical analyses, conceived, drafted, reviewed and revised the article for intellectual content and approved the final version for publication. JL reviewed and refined the survey instrument, reviewed statistical analyses, conceived, reviewed and revised the article for intellectual content and approved the final version for publication.

\section{Ethics approval and consent to participate}

The study was approved by the North Coast NSW Human Research Ethics Committee (LNR116) on 24 April 2015. Return of the completed survey was accepted as consent. Additionally, the survey form sought written consent for follow-up of vaccination records.

\section{Consent for publication}

Not applicable.

\section{Competing interests}

The authors declare that they have no competing interests.

\section{Publisher's Note}

Springer Nature remains neutral with regard to jurisdictional claims in published maps and institutional affiliations.

\section{Author details}

${ }^{1}$ Director, North Coast Public Health, Mid North Coast Local Health District, PO Box 126, Port Macquarie, NSW 2444, Australia. ${ }^{2}$ Associate Professor, Sydney Nursing School and, Principal Research Fellow, School of Public Health, University of Sydney, 88 Mallett Street (MO2), Sydney, NSW 2050, Australia.

Received: 1 November 2017 Accepted: 28 March 2018

Published online: 02 May 2018

\section{References}

1. Robison SG, Groom H, Young C. Frequency of alternative immunization schedule use in a metropolitan area. Pediatrics. 2012; https://doi.org/10. 1542/peds.2011-3154.

2. Smith MJ, Marshall GS. Navigating parental vaccine hesitancy. Pediatr Ann 2010; https://doi.org/10.3928/00904481-20100726-05.

3. Kennedy A, LaVail K, Nowak G, Basket M, Landry S. Confidence about vaccines in the United States: understanding parents' perceptions. Health Aff (Millwood). 2011; https://doi.org/10.1377/hlthaff.2011/0396.

4. Larson HJ, Cooper LZ, Eskola J, Katz SL, Ratzan S. Addressing the vaccine confidence gap. Lancet. 2011; https://doi.org/10.1016/S0140-6736(11)60678-8.

5. National Vaccine Advisory Committee. Assessing the state of vaccine confidence in the United States: recommendations from the National Vaccine Advisory Committee: NVA Committee; 2016. Available from: http:// www.hhs.gov/sites/default/files/nvpo/nvac/reports/nvac-vaccine-confidencepublic-health-report-2015.pdf. Accessed 19 March 2016

6. The London School of Hygiene \& Tropical Medicine. The state of vaccine confidence 2015: TVC Project; 2015. Available from: http://www.vaccineconfidence. org/research/the-state-of-vaccine-confidence/. Accessed 13 July 2017

7. Centre for Epidemiology and Evidence. 2009-2010 summary report from the new South Wales child health survey. Sydney: NMo Health. p. 2012. Available from:http://www.health.nsw.gov.au/surveys/child/Pages/childhealth-survey-09-10.aspx

8. Centre for Epidemiology and Research. New South Wales child health survey 2001: NSW Public Health Bull; 2002. 13(S-3). NSW Department of Health, Available from: http://www.health.nsw.gov.au/phb/Publications/ NSW-child-health-survey-2001.pdf. Accessed 22 April 2016

9. Australian Institute of Health and Welfare. Healthy communities: immunisation rates for children in 2015-16. Canberra: Australian Institute of Health and Welfare; 2017. Available from: http://www. myhealthycommunities.gov.au/our-reports/immunisation-rates-for-children/ june-2017. Accessed 8 June 2017

10. Health and Social Care Information Centre. NHS Immunisations statistics: England 2015-16. London: HaSCl Centre. Available from: http://content. digital.nhs.uk/catalogue/PUB21651/nhs-imms-stat-eng-2015-16-rep.pdf. Accessed 2 July 2017

11. King C, Leask J. The impact of a vaccine scare on parental views, trust and information needs: a qualitative study in Sydney. Australia BMC Public Health. 2017; https://doi.org/10.1186/s12889-017-4032-2.

12. Velan B, Boyko V, Lerner-Geva L, Ziv A, Yagar Y, Kaplan G. Individualism, acceptance and differentiation as attitude traits in the public's response to vaccination. Hum Vaccin Immunother. 2012; https://doi.org/10.4161/hv.21183. 
13. Lawrence $G$, Hull B, Mclntyre C, Mclntyre P. Reasons for incomplete immunisation among Australian children: A national survey of parents. Aust Fam Physician. 2004;33(7):568-571.

14. Ward PR, Attwell K, Meyer SB, Rokkas P, Leask J. Understanding the perceived logic of care by vaccine-hesitant and vaccine-refusing parents: A qualitative study in Australia. PLoS One. 2017;12(10):e0185955. https://doi. org/10.1371/journal.pone.0185955.

15. Beard FH, Hull BP, Leask J, Dey A, Mclntyre PB. Trends and patterns in vaccination objection, Australia, 2002-2013. Med J Aust. 2016; https:// doi.org/10.5694/mja15.01226.

16. Hull BL. GL; McIntyre, CR; Mcintyre, PB. Aust Fam Physician: Is low immunisation coverage in Australian inner urban areas due to low uptake or poor notification; 2003.

17. Hull BP, Mclntyre PB. Timeliness of childhood immunisation in Australia. Vaccine. 2006; https://doi.org/10.1016/j.vaccine.2006.02.049.

18. National Health Performance Authority. Healthy communities: immunisation rates for children in 2014-15. Canberra National Health Performance Authority, February 2016. Available from:http://www.myhealthycommunities. gov.au/our-reports/immunisation-rates-for-children/february-2016. Accessed 17 Feb 2016.

19. Wroe AL, Turner N, Salkovskis PM. Understanding and predicting parental decisions about early childhood immunizations. Health Psychol. 2004; https://doi.org/10.1037/0278-6133.23.1.33.

20. Gust DA, Darling N, Kennedy A, Schwartz B. Parents with doubts about vaccines: which vaccines and reasons why. Pediatrics. 2008; https://doi.org/ 10.1542/peds.2007-0538

21. Opel DJ, Taylor JA, Mangione-Smith R, Solomon C, Zhao C, Catz S, et al. Validity and reliability of a survey to identify vaccine-hesitant parents. Vaccine. 2011; https://doi.org/10.1016/j.vaccine.2011.06.115.

22. Henrikson NB, Anderson ML, Opel DJ, Dunn J, Marcuse EK, Grossman DC. Longitudinal trends in vaccine hesitancy in a cohort of mothers surveyed in Washington state, 2013-2015. Public Health Rep. 2017; https://doi.org/10. $1177 / 0033354917711175$

23. O'Connor AM. User manual - stage of decision making. Vol. 2003, 2003 update edition. Pp. user manual. Ottawa: Ottawa Hospital Research Institute (c) 2000; 2003. User manual

24. O'Connor AM. Validation of a decisional conflict scale. Med Decis Mak. 1995; https://doi.org/10.1177/0272989X9501500105.

25. Opel DJ, Mangione-Smith R, Taylor JA, Korfiatis C, Wiese C, Catz S, et al. Development of a survey to identify vaccine-hesitant parents the parent attitudes about childhood vaccines survey. Human Vaccines. 2011; https://doi.org/10.4161/hv.7.4.14120.

26. Opel DJ, Taylor JA, Zhou C, Catz S, Myaing M, Mangione-Smith R. The relationship between parent attitudes about childhood vaccines survey scores and future child immunization status: a validation study. JAMA Pediatr. 2013; https://doi.org/10.1001/jamapediatrics.2013.2483.

27. Brown KF, Shanley R, Cowley NAL, van Wijgerden J, Toff $P$, Falconer $M$, et al. Attitudinal and demographic predictors of measles, mumps and rubella (MMR) vaccine acceptance: development and validation of an evidence-based measurement instrument. Vaccine. 2011; https://doi.org/ 10.1016/j.vaccine.2010.12.030.

28. Kennedy A, Basket M, Sheedy K. Vaccine attitudes, concerns, and information sources reported by parents of young children: results from the 2009 HealthStyles survey. Pediatrics; 2011. https://doi.org/10.1542/peds.2010-1722N.

29. Tickner S, Leman PJ, Woodcock A. The immunisation beliefs and intentions measure (IBIM): predicting parents' intentions to immunise preschool children. Vaccine; 2010. https://doi.org/10.1016/j.vaccine.2010.02.083.

30. Leask J, Chow M, Willaby H, Pemberton S. Parental attitudes towards childhood vaccination in Australia. In: PHAA 14th National Immunisation Conference. Melbourne; 2014.

31. O'Connor AM: User manual - decisional conflict scale - (16 item statement format). 2010 Update edition. Ottawa: Ottawa Hospital Research Institute; (C 1993.

32. Larson HJ, Jarrett C, Schulz WS, Chaudhuri M, Zhou Y, Dube E, et al. Measuring vaccine hesitancy: the development of a survey tool. Vaccine. 2015; https://doi.org/10.1016/j.vaccine.2015.04.037.

33. Department of Human Services. National due and overdue rules for immunisation - version 1.0 2016. Available from: https://www humanservices.gov.au/sites/default/files/documents/acir-due-overdue-rules. docx. Accessed 21 June 2017.

34. SAS $^{\circledR} 9.4$ for Windows, SAS Institute Inc [http://www.sas.com/en_us/ software/sas9.html].
35. Centre for Epidemiology and Evidence. New South Wales mothers and babies. Sydney: NSW Ministry of Health; 2015. Available from:http://www.health.nsw. gov.au/hsnsw/Pages/mothers-and-babies-2015.aspx. Accessed 26 Feb 2017

36. Fleiss JL, Levin B, Paik MC. In: Balding NACCDJ, Fisher NI, Johnstone IM, Kadane JB, Ryan LM, Scott DW, Smith AFM, Teugels JL, editors. Statistical methods for rates and proportions - THIRD EDITION. Hoboken: John Wiley \& Sons, Inc.; 2003.

37. Danchin MH, Costa-Pinto J, Attwell K, Willaby H, Wiley K, Hoq M, et al. Vaccine decision-making begins in pregnancy: Correlation between vaccine concerns, intentions and maternal vaccination with subsequent childhood vaccine uptake. Vaccine; 2017. In press. https://doi.org/10.1016/j.vaccine.2017.08.003.

38. Biro MA. What has public health got to do with midwifery? Midwives' role in securing better health outcomes for mothers and babies. Women Birth. 2011; https://doi.org/10.1016/j.wombi.2010.06.001.

39. Pearce C, Leask J, Ritchie J. Tapping midwives' views about the neonatal hepatitis B vaccine: how welcome is a move towards a health promoting orientation? Health Promot J Austr. 2008;19:161-163.

40. Leask J, Quinn HE, Macartney K, Trent M, Massey P, Carr C, et al. Immunisation attitudes, knowledge and practices of health professionals in regional NSW. Aust N Z J Public Health. 2008; https://doi.org/10.1111/j.17536405.2008.00220.x.

41. Russo G, Miglietta A, Pezzotti P, Biguioh RM, Bouting Mayaka G, Sobze MS, et al. Vaccine coverage and determinants of incomplete vaccination in children aged 12-23 months in Dschang, West Region, Cameroon: a crosssectional survey during a polio outbreak. BMC Public Health. 2015,15:630-640. https://doi.org/10.1186/s12889-015-2000-2.

42. Adedire EB, Ajayi I, Fawole Ol, Ajumobi O, Kasasa S, Wasswa P, et al. Immunisation coverage and its determinants among children aged 12-23 months in Atakumosa-west district, Osun State Nigeria: a cross-sectional study. BMC Public Health. 2016;16:905-912. https://doi.org/10.1186/s12889016-3531-x.

43. Saitoh A, Saitoh A, Sato I, Shinozaki T, Kamiya H, Nagata S. Effect of stepwise perinatal immunization education: a cluster-randomized controlled trial. Vaccine. 2017; https://doi.org/10.1016/j.vaccine.2017.01.069.

44. Browne M, Thomson P, Rockloff MJ, Pennycook G. Going against the herd: psychological and cultural factors underlying the 'vaccination confidence gap'. PLoS One. 2015; https://doi.org/10.1371/journal.pone.0132562.

45. WHO Regional Office for Europe. Vaccines and trust - how concerns arise and the role of communication in mitigating crises. Copenhagen: WH Organization. Available from: http://www.euro.who.int/en/health-topics/ disease-prevention/vaccines-and-immunization/publications/2017/ vaccination-and-trust-2017

46. Beard FH, Leask J, Mclntyre PB. No jab, no pay and vaccine refusal in Australia: the jury is out. Med J Aust. 2017; https://doi.org/10.5694/mja16.00944.

47. Vannice KS, Salmon DA, Shui I, Omer SB, Kissner J, Edwards KM, et al. Attitudes and beliefs of parents concerned about vaccines: impact of timing of immunization information. Pediatrics. 2011; https://doi.org/10.1542/peds. 2010-1722R.

48. Saitoh A, Saitoh A, Sato I, Shinozaki T, Kamiya H, Nagata S. Improved parental attitudes and beliefs through stepwise perinatal vaccination education. Hum Vaccin Immunother. 2017; https://doi.org/10.1080/ 21645515.2017.1368601

49. Goldenberg MJ. Public misunderstanding of science? Reframing the problem of vaccine hesitancy. Perspect Sci. 2016; https://doi.org/10.1162/ POSC_a_00223.

50. Pluviano S, Watt C, Della SS. Misinformation lingers in memory: failure of three pro-vaccination strategies. PLoS One. 2017; https://doi.org/10.1371/ journal.pone.0181640.

51. Leask J, Cheater F, Kinnersley P, Willaby HW, Danchin M. Presumptive initiations in vaccine discussions with parents: acquiescence but at what cost? [letter to the editors]. Pediatrics. 2013;132(6):13.

52. Opel DJ, Taylor JA, Mangione-Smith R, Robinson JD. Re: Presumptive initiations in vaccine discussions with parents: acquiescence but at what cost? [letter to the editors]. Pediatrics. 2014;132(6):11.

53. Carpenter DM, Geryk LL, Chen AT, Nagler RH, Dieckmann NF, Han PK. Conflicting health information: a critical research need. Health Expect; 2015. https://doi.org/10.1111/hex.12438.

54. Benin AL, Wisler-Scher DJ, Colson E, Shapiro ED, Holmboe ES. Qualitative analysis of mothers' decision-making about vaccines for infants: the importance of trust. Pediatrics. 2006; https://doi.org/10.1542/peds.2005-1728. 